\title{
O TRATAMENTO INDEXAL DE FOTOGRAFIAS PARA COMPOSIÇÃO DA MEMÓRIA INSTITUCIONAL
}

\section{THE INDEXAL TREATMENT OF PHOTOGRAPHS FOR COMPOSITION OF THE INSTITUTIONAL MEMORY}

\author{
Valeska Paulino Nogueiraa \\ Gracy Kelli Martins ${ }^{b}$
}

\begin{abstract}
RESUMO
Introdução: As imagens fotográficas constituem-se como importantes documentos, possuidores de valioso potencial em termos informacionais, históricos e culturais, que são constituintes da memória. Nesse sentido, o estudo discorre sobre o valor da fotografia enquanto documento constituinte da memória institucional, apresentando aspectos relevantes da literatura sobre a análise documentária, com ênfase no processo de indexação, tendo como objeto de investigação o acervo de fotografias digitais da Universidade Federal do Cariri (UFCA). Objetivo: Desenvolver estratégias de categorização e representação indexal que contemplam os aspectos relacionados ao conteúdo das fotografias da UFCA, armazenadas na plataforma Flickr. Metodologia: Através de uma abordagem de caráter qualitativo, realizou-se uma análise documental e interpretativa relacionada aos processos de produção e representação das fotografias da UFCA. Resultados: Tal análise possibilitou a identificação e apresentação das especificidades deste tipo de documento e as suas lógicas especiais de tratamento e contribuições para a construção de critérios de indexação de imagens fotográficas, que visam nortear o desenvolvimento de uma política de indexação para a Instituição. Conclusões: Diante da inexistência de qualquer direcionamento acerca dos critérios de indexação para o acervo fotográfico digital da UFCA, sugerimos a criação de um documento que elenque os aspectos importantes em relação ao procedimento de tratamento indexal dos documentos imagéticos, considerado indispensável para garantir a preservação da memória institucional da universidade
\end{abstract}

Descritores: Análise documentária. Fotografia. Indexação. Memória Institucional.

\footnotetext{
a Mestra em Biblioteconomia, pela Universidade Federal do Cariri (UFCA). E-mail: valeska.nogueira@ufca.edu.br

b Doutora pelo Programa de Pós-Graduação em Ciência da Informação da Universidade Estadual Paulista Júlio de Mesquita Filho (UNESP). Professora de Biblioteconomia da Universidade Federal da Paraíba (UFPB). E-mail: gracykelli@gmail.com
} 


\section{INTRODUÇÃO}

O presente artigo propõe-se a apresentar algumas reflexões construídas a partir de uma pesquisa realizada no Mestrado Profissional em Biblioteconomia, da Universidade Federal do Cariri (UFCA), cuja pergunta de partida versava sobre o lugar/importância da fotografia enquanto documento constitutivo da memória institucional, tendo como recorte empírico o processo de indexação dos arquivos fotográficos institucionais, em formatos digitais, da UFCA.

Pensando as fotografias pelo viés documental e de seu potencial informacional, surgem questionamentos sobre quais as maneiras de aproveitamento e de seu efetivo uso pelos indivíduos e grupos sociais. Nesse sentido, abordamos a temática relacionada à organização e representação da informação dos documentos fotográficos, enfatizando os processos de representação indexal e suas contribuições para a recuperação da informação e o acesso que garantem entre tantos benefícios a constituição de uma memória institucional.

Nesse contexto os estudos propostos por Erwin Panofsky (1979 apud SMIT, 1996) subsidiam o entendimento sobre a análise documentária de fotografias, ampliando e evidenciando a necessidade da análise do material fotográfico em níveis pré-iconográfico, iconográfico e iconológico ${ }^{1}$ que se configuram como norteadores para uma representação abrangente das fotografias, inserindo vertentes que contemplam aspectos relacionados ao seu caráter histórico e contextual, que são permeadas pelo exercício de identificação das mensagens presentes nos documentos e pelo exercício interpretativo de seus "valores simbólicos". Tais níveis em conjunto com as propostas de Shatford (1986), que contemplam as categorias ${ }^{2} D E$ genérico, $D E$ específico e SOBRE, nos direcionaram para as especificidades da análise documentária de fotografias.

Nesta investigação também destacamos as nuances relativas aos documentos fotográficos e sua relação com a memória institucional. Segundo

\footnotetext{
${ }^{1}$ Iconografia: ramo da História da Arte que se preocupa com o tema ou a mensagem contida nas obras de arte, em oposição à sua forma; pode ser considerada uma descrição analítica de imagens. Iconologia: ramo da História da Arte que se preocupa com a descoberta e a interpretação dos valores simbólicos; é uma iconografia interpretativa que trabalha mais com a síntese (PANOFSKY, 1991 apud MANINI, 2002).

2 De acordo com as categorias de Shatford (1986) uma fotografia pode ser, em nível genérico, DE alguma coisa, em nível específico, DE alguma coisa e SOBRE alguma coisa.
} 
Possamai $(2008$, p.2) as fotografias comportam um rico "[...] universo a ser explorado para a construção de sentidos e significações sociais" e para a "constituição e preservação da memória". Nessa perspectiva, a representação indexal deve levar em conta o potencial memorialístico presente nas fotografias o contexto em que estão inseridas e a qual público interessará. De acordo com Barthes (1984) percebemos que $o$ ato de fotografar permite que se capture e materialize um dado instante que, inserido no contexto de uma época, é capaz de simbolizar e referenciar fragmentos de uma realidade que existiu num momento passado.

Reconhecendo que os documentos fotográficos são um meio de registro e de comunicação que ao serem utilizados podem servir para informar, divulgar e registrar ações e atividades do cotidiano nos mais diversos contextos, justificam-se os esforços deste estudo em prol de um melhor entendimento sobre suas formas de produção e para o estabelecimento e aprimoramento de processos de tratamento, organização e representação da informação, com ênfase na indexação de documentos fotográficos e como esse processo gera um impacto significativo na memória institucional.

A pesquisa buscou, através de suas verificações, análises e reflexões, apontar direcionamentos e propor critérios que orientem os processos de indexação de fotografias produzidas no âmbito de uma instituição universitária, mais especificamente da UFCA, tendo em vista que tais processos influenciam decisivamente na eficiência da representação documental e na qualidade da recuperação informacional.

\section{PROCEDIMENTOS METODOLÓGICOS}

A pesquisa foi realizada junto ao setor da Diretoria de Comunicação (DCOM), responsável pela produção e armazenamento dos materiais fotográficos referentes à Instituição. Envolveu a observação sistemática, que de acordo com Marconi; Lakatos (2010, p. 176) é o tipo de observação em que "[...] o observador sabe o que procura e o que carece de importância em determinada situação", sendo objetivo e reconhecendo as possíveis correções a serem feitas. 
Embasados por este tipo de observação empreendemos conversas com profissionais da DCOM para a verificação dos processos empregados para o tratamento das fotografias produzidas pela UFCA e a verificação da adoção das ferramentas da plataforma Flickr ${ }^{3}$, que é utilizada para o armazenamento e disponibilização do material fotográfico pela Instituição que, por ser uma Universidade jovem, quanto à sua constituição4, tem implementado serviços e recursos alternativos e gratuitos, visando a sua sustentabilidade financeira.

Consideramos importante ressaltar que os serviços oferecidos pelo Flickr contemplam o aspecto colaborativo da disponibilização, organização e descrição de conteúdos imagéticos. No tocante à descrição das fotografias, o Flickr apresenta como possibilidade a inserção de textos (título do álbum e notas explicativas) e $\operatorname{Tags}^{5}$ que são recursos utilizados para representação textual, através de etiquetas de marcação, em relação à imagem, como uma forma livre de indexação. A proposta do Flickr é que a indexação das imagens seja feita pelos próprios usuários através dos textos e Tags e que estes funcionem como termos que serão responsáveis pela recuperação do conteúdo compartilhado.

A pesquisa foi pautada na averiguação do fluxo das fotografias da UFCA, identificando o percurso desde os momentos que antecedem os registros fotográficos até o momento da inserção na plataforma colaborativa Flickr. Com uma abordagem de caráter qualitativo sobre uma realidade específica, relacionada aos processos de produção e representação das fotografias na referida Instituição, empreendemos a análise das fotografias institucionais armazenadas no Flickr, que até a última visualização, no mês de junho de 2019, representam um acervo composto por 9.618 imagens fotográficas. Deste total,

\footnotetext{
${ }^{3} \mathrm{https}: / /$ www.flickr.com/ Um website de hospedagem e compartilhamento de imagens fundado por Stewart Butterfield e Caterina Fake em 2004, que de acordo com dados de apresentação do site, possui atualmente 13 bilhões de fotos hospedadas.

${ }^{4}$ A Universidade Federal do Cariri (UFCA) foi criada pela Lei 12.826, de 05 de junho de 2013, a partir de um desmembramento da Universidade Federal do Ceará.

5 As tags são palavras que servem como uma etiqueta e ajudam na hora de organizar conteúdos colaborativos, agrupando os que receberam a mesma marcação, facilitando a localização de conteúdos/materiais semelhantes. Comumente utilizadas em imagens na internet, estão relacionadas às Folksonomias (em inglês, folksonomy), "um neologismo utilizado para explicar o recente fenômeno na web em que pessoas comuns descrevem conteúdos (notícias, blogs, vídeos, imagens, sites, etc) - através de tags ou labels (palavras-chaves, não necessariamente presentes no conteúdo sendo descrito)" (GOUVÊA; LOH, 2007, p.1).
} 
30 fotografias foram selecionamos como recorte, compondo o caso concreto de análise. A escolha levou em consideração a verificação das principais temáticas ${ }^{6}$ contempladas nas fotografias dispostas nos álbuns pertencentes à UFCA, de modo a possibilitar que o recorte retratasse o cotidiano da Instituição. As fotografias foram analisadas no que se refere a sua indexação (atribuição de Tags) para a verificação da proximidade das mesmas com as propostas metodológicas dos autores ${ }^{7}$ sobre a representação indexal, bem como a identificação das reais necessidades e características que devem ser contempladas e respeitadas, respectivamente, para a proposição de critérios de indexação que conduzem o estudo para uma vertente que tem como finalidade a aplicação prática, dirigida à solução de problemas e melhoria dos processos da UFCA.

A partir disso a análise se configurou pela existência de dois momentos distintos:

1. Identificação do decurso das fotografias, desde a sua coleta, passando pelo tratamento até a sua armazenagem e disponibilização, ou seja, a averiguação de todo o percurso destas;

2. Análise e interpretação de um recorte do material fotográfico, a partir dos dados e critérios estruturados na metodologia.

Realizamos a análise acerca do cenário da produção e organização das fotografias produzidas na UFCA, visando perceber e relatar suas características e, a partir da compreensão de seus aspectos, propor critérios de indexação. Consideramos as abordagens de Lancaster (2004), pautadas na definição das etapas que são efetuadas no processo de indexação: análise conceitual e tradução. Em seu aspecto conceitual, adotamos o entendimento de Smit (1996) que, embasada por Dubois (1994), visualiza as fotografias como "traços do real", que contemplam conteúdos capazes de referenciar contextos e sugerir interpretações memorialísticas e históricas. Assim, as imagens foram analisadas sob a perspectiva de Smit (1996) e de Panofsky (1979) que aponta os níveis préiconográfico, iconográfico e iconológico para análise das imagens.

\footnotetext{
6 Tais como: inauguração de prédios; colações de grau; eventos acadêmicos; assinatura de documentos institucionais;

7 G. Bléry (1981); Panofsky (1979); Shatford (1986); Smit (1996).
} 
Na abordagem de Panofsky (1979), no nível pré-iconográfico, as imagens são apresentadas de forma geral, sem riqueza de detalhes específicos; no nível iconográfico, as imagens são descritas com maior riqueza de detalhes, contemplando as ações e os elementos observados nas imagens; já no nível iconológico, o assunto da imagem fica bem delineado através do detalhamento de elementos que estejam ou não presentes na imagem.

Tendo por base os níveis de análise de Panofsky (1979), Shatford (1986) propomos a identificação de aspectos que respondam DE que é uma imagem e SOBRE o que é uma imagem. Tais aspectos foram convertidos em descritores que contemplam as categorias DE genérico, DE específico e SOBRE. Assim, como no delineamento dos níveis de Panofsky (1979), nas categorias de Shatford (1986), os descritores diferem no grau de detalhamento, em relação aos elementos das imagens, que podem se apresentar de forma mais genérica ou de forma mais específica. As imagens também foram analisadas de acordo com o viés proposto por G. Bléry (1981) e discutido por Smit (1996) ao apresentarem as categorias QUEM, ONDE, QUANDO, COMO e O QUE como etapas da análise documentária, conforme estruturado no Quadro 1:

\section{Quadro 1 - Quadro de análise das fotografias}

\begin{tabular}{|c|c|c|c|c|c|}
\hline & \multicolumn{4}{|l|}{ Categorias } & \\
\hline & Quem/O Que & Onde & Quando & Como & \\
\hline De Genérico & & & & & Pré-iconográfico \\
\hline De Específico & & & & & Iconográfico \\
\hline Sobre & & & & & Iconológico \\
\hline
\end{tabular}

Fonte: (SMIT, 1996; MANINI, 2002 - Adaptado pelas autoras).

Após a seleção das fotografias verificamos as Tags expostas na descrição na base Flickr e realizamos a análise conceitual e a atribuição de termos, utilizando como instrumento metodológico o quadro de análise das fotografias (Quadro 1), que foi desenvolvido com base nos critérios e categorias propostos por Smit (1996) e Manini (2002) e nas propostas de análise. Durante a verificação das fotografias, tendo em vista o nível de descrição, observamos se as Tags contemplavam as categorias e critérios apresentados no Quadro 1, considerados como requisitos necessários para que se ateste maior nível de qualidade na indexação realizada. A identificação de lacunas na representação 
impulsionou a proposição dos termos para a complementação da representação, proporcionando ao sistema uma melhor consistência e favorecendo a recuperação das fotografias. O estudo possibilitou a sugestão de critérios de indexação que poderão servir de base para a elaboração de uma política de indexação para a Instituição.

\section{O DOCUMENTO FOTOGRÁFICO NA PERSPETIVA DA ORGANIZAÇÃO DA INFORMAÇÃO}

Baseadas em estudos sobre as contribuições de teóricos acerca da documentação e dos documentos Ortega e Lara (2009, p. 122) consideram que:

A noção de documento relaciona-se à sua condição de informatividade, ou seja, às suas possibilidades de informar. Mais do que a informação, é a informatividade que permite entrever o jogo intertextual que caracteriza os processos de recepção determinando os critérios de relevância para que algo seja considerado informativo.

Pontuamos as contribuições de Suzanne Briet (1951) a partir da publicação de Qu'est-ce que la documentation?, em que explicita definições sobre o documento que enfatizam o caráter do registro informacional, sua capacidade de promover uma representação, de reproduzir acontecimentos, de testemunho e de "prova de um fenômeno físico ou intelectual". Manini (2002, p. 35) considera que documento "é a concretização de toda informação registrada (e útil, para ser guardada) - independente de qual seja o suporte desta informação - passível de transmitir conhecimento; é o testemunho da realização da atividade humana".

Analisando as discussões e conceituações acerca dos propósitos da Documentação e dos conceitos atribuídos ao documento percebe-se uma ênfase na questão do potencial informacional dos documentos. O fator que motiva a produção documental é o registro de informações, feito através de suportes que possibilitam a transmissão e o acesso.

De acordo com Brascher e Café (2008, p. 05) a organização da informação (OI) é entendida neste contexto como um "processo que envolve a descrição física e de conteúdo dos objetos informacionais". Tais processos representam 
facilitadores quando se pensa na recuperação da informação, já que fornecem metodologias de ordenação e descrição. Com um entendimento de que as atenções não devem ser voltadas apenas para o documento enquanto suporte e sim para as informações que estes possuem, ou seja, para sua substância, em uma ação contínua, os estudos de OI idealizam e desenvolvem instrumentos, produtos e procedimentos que possuem a finalidade de reunir, tratar, expressar e disseminar o potencial informacional dos documentos, com vista a possibilitar que os usuários possam recuperá-las, suprindo suas necessidades.

Promovendo uma aproximação com o interesse do presente estudo voltamo-nos em direção ao pensamento de Smit (1996, p. 29), considerando que "a proposição de uma metodologia de análise da fotografia supõe um entendimento da essência desta, daquilo que a caracteriza, das razões pelas quais é produzida e, sobretudo, das condições em que será utilizada", para que se desenvolva uma efetiva representação deste documento. $A$ análise de documentos fotográficos requer que os mesmos sejam lidos visualmente, suscitando um processo associativo de ideias e reflexões que possibilitem sua interpretação. Em sua análise devem ser percebidas suas particularidades, que sofrem influências relacionadas à época de produção e ao seu contexto, suas características, razões de sua produção e as formas como seus usuários farão uso delas. Assim como ocorre na leitura de documentos textuais, a leitura de uma imagem não encerra em si uma interpretação única de seu conteúdo, devido à sua natureza polissêmica e a seu alto teor de subjetividade, que influenciarão fortemente as formas de indexação.

Dubois (1994) enfatiza a questão do uso da fotografia e apresenta três fases no que diz respeito à produção e ao uso de imagens fotográficas, sendo elas:

- A fotografia como espelho do real;

- A fotografia como transposição do real;

- A fotografia como traço do real.

Ao analisar tais fases, Smit (1996) nos oferece a ideia de que sob a perspectiva de que as fotografias, vistas como traço do real, seriam assimiladas ao conceito de índice, sendo representações de um "traço do real" de um aspecto 
de um objeto, as fotografias incorporariam a "relatividade cultural da percepção da imagem". Assim como Dubois (1994) e Smit (1996), apropriamo-nos da visão que considera a fotografia como índice por voltarmos nossos estudos à linha do valor das fotografias enquanto documento que registra momentos e suscita sentidos. Os códigos visuais contidos em fotografias apresentam conteúdos que referenciam um contexto e época específicos que decodificados sugerem interpretações diversas de uma realidade. Pois como sugere Kossoy (2009, p. 44 ) "os receptores já trazem em si suas próprias imagens mentais preconcebidas acerca de determinados assuntos". Estas imagens mentais, atravessadas pelo caráter polissêmico das fotografias suscitam, como dito anteriormente, interpretações múltiplas do real que variam de acordo com as correlações que os indivíduos farão, baseados em seus conhecimentos e repertórios culturais, sociais e políticos.

Tendo como base os estudos de Erwim Panofsky (1979) sobre iconografia e iconologia e considerando as argumentações de Kossoy (2009) e Smit (1996) sobre os níveis de análise, consideramos que o pré-iconográfico seria a identificação do objeto fotografado, do referente em si, com o relacionamento e a pormenorização dos elementos que compõem a imagem. Na visão de Kossoy (2009, p. 58) a análise iconográfica é capaz de revelar "dados concretos sobre o documento no que diz respeito à sua materialização documental e aos detalhes icônicos nele gravados". Este nível estaria relacionado com o valor mítico que os elementos e a disposição deles teriam em uma fotografia, ou seja, seria a análise descritiva do objeto em função da observação da representatividade e significação da imagem. Para Kossoy (2009, p. 59) no nível de interpretação iconológico a fotografia é vista como "uma representação a partir do real, uma representação onde se tem registrado um aspecto selecionado daquele real". Assim, o iconológico propõe uma interpretação do significado intrínseco da imagem, levando em consideração aspectos do contexto social, cultural, ideológico, dentre outros, que sendo constituintes de seu conteúdo possibilitam a interpretação de um recorte, repleto de sentido, da realidade de uma época, representado através da imagem. Mesmo que intrinsecamente relacionada ao referente, as fotografias não podem ser interpretadas e compreendidas de forma 
desvinculada dos aspectos relacionados ao seu processo de construção.

Shatford (1986, p. 43, apud Smit, 1996, p. 31) propõe a diferenciação entre DE e SOBRE: "A IMAGEM É DE QUE? e A IMAGEM É SOBRE O QUÊ?". Manini (2002, p. 73) afirma que "na distinção entre o DE (Genérico e Específico) e o SOBRE, temos que o DE é mais objetivo e consensual; já o SOBRE mais subjetivo e de consenso limitado, estando esta limitação vinculada à polissemia da imagem e ao repertório do observador". Ao discorrer sobre os processos de descrição de imagens Smit nos apresenta as categorias, inicialmente postuladas por G. Bléry, QUEM, ONDE, QUANDO, COMO e O QUE e afirma que "Se a descrição responde às perguntas QUEM (seres vivos), ONDE (ambiente), QUANDO (tempo), ONDE (espaço), O QUE (ação) e COMO (técnica), poderemos supor que nenhum detalhe realmente importante tenha sido esquecido" (SMIT, 1987, p. 109).

As fotografias, em conjunto com o texto verbal, possuem valor documental, pois comportam um potencial informativo que, além de atestar credibilidade, estimulam nos espectadores sentidos históricos de fatos, criando todo um repertório visual, histórico e memorativo de uma época, que precisam ser identificados nas imagens.

\section{FOTOGRAFIA E MEMÓRIA INSTITUCIONAL}

As fotografias figuram como referencial de temporalidade e testemunho, assumindo, assim, uma dimensão histórica e social, à medida que se constituem como meios de registro e representação feitas a partir do real e que possibilitam o contato com aspectos de realidades anteriores, configurando-se como valiosas fontes documentais para o entendimento do passado e o registro da memória, seja ela individual ou coletiva.

Vislumbramos as imagens fotográficas enquanto documento em acordo com Madio; Fujita (2008, p. 253) que em suas abordagens sobre as imagens fotográficas na condição de documento entendem "a fotografia como resultado de uma função, uma intencionalidade, seja institucional ou particular. [...] $O$ documento só existe a partir de uma ação, de uma vontade que se efetiva, se 
concretiza em uma materialidade". Assim, identificamos as imagens fotográficas como documentos importantes para o estudo do passado, à medida que possibilitam uma representação de aspectos de uma realidade e uma proximidade com um momento anterior, servindo de testemunho. Esses fragmentos do passado nos remetem à questão da memória que de acordo com as abordagens de Pollak (1989, p. 7) pode ser vista da seguinte forma:

A memória, essa operação coletiva dos acontecimentos e das interpretações do passado que se quer salvaguardar, se integra, em tentativas mais ou menos conscientes de definir e de reforçar sentimentos de pertencimento e fronteiras sociais entre coletividades.

A memória comporta ações sucedidas no passado, compondo a consciência dos indivíduos e proporcionando aos mesmos a sensação de pertencimento. Dessa forma, as imagens servem de instrumento à nossa memória e de afirmação à nossa existência, sendo essenciais para o reconhecimento e identidade de um povo, de uma sociedade. Ressaltamos que os indivíduos devem encarar uma fotografia e suas representações de forma reflexiva e interpretativa, buscando perceber as singularidades históricas e sociais características do tempo e do espaço de sua produção, diretamente influenciadas pelo processo de criação/construção do fotógrafo, pois de acordo com Kossoy (2009, p. 27) "o assunto, tal como se acha representado na imagem fotográfica, resulta de uma sucessão de escolhas; é fruto de um somatório de seleções de diferentes naturezas - idealizadas e conduzidas pelo fotógrafo".

Pensando memória atrelada ao seu contexto, às suas influências constituintes e atribuidoras de sentidos e nos afastando de uma memória unificadora, focamos os registros imagéticos, considerando importante vislumbrar o estudo sob a perspectiva de uma memória reconhecida como institucional. De acordo com Barbosa (2010, p. 11), a memória Institucional [...] consiste em uma (re) construção de fatos e acontecimentos significativos da trajetória e das experiências da organização, selecionados e (re) organizados com o objetivo de estimular o processo de (re) construção de uma identidade comum entre esta e seus públicos de interesses. [...] O papel da Memória Institucional é, então, (re) construir o futuro por meio do passado e da atualidade, 
no qual a identificação dos elementos da cultura e da identidade organizacional serão futuros predominantes.

Nesse sentido a memória institucional oferece aos indivíduos possibilidades de compreender o passado através de materializações de fragmentos do vivido, de reconstruções de fatos e acontecimentos, de suas rotinas administrativas, que possibilitam construções de identidades, que em nossa compreensão devem ser permeadas pelas singularidades. As instituições produzem um legado memorativo que é resultado de uma série de práticas cotidianas pessoais e/ou coletivas e neste cerne a memória social ou memória coletiva $^{8}$ contribui para a constituição da memória institucional, que reforça os vínculos associativos e as possibilidades de compartilhamento.

\subsection{O ACERVo Digital de Fotografias dA UFCA}

O contexto educacional, em que está inserido o foco de estudo deste trabalho, é dinâmico e marcado pelos processos de produção e buscas de informações, científicas ou não. Criada em 05 de junho de 2013, através da Lei 12.826, a Universidade Federal do Cariri é vinculada ao Ministério da Educação e possui sede na Cidade de Juazeiro do Norte, no Ceará. Compõem a Universidade cinco campi, distribuídos nas Cidades de Juazeiro do Norte, Icó, Brejo Santo, Crato e Barbalha que ofertam 16 cursos de graduação, além de cursos de pós-graduação.

Componente dos órgãos suplementares da organização administrativa da UFCA, a Diretoria de Comunicação (DCOM), que teve sua criação pautada na Resolução n¹0/2016/Consup/UFCA, tem como objetivo, sob os pilares da comunicação organizacional, oferecer produtos e ações sistematizadas de comunicação para os públicos internos (estudantes, professores, servidores técnicos) e externos (veículos de comunicação, movimentos sociais, órgãos públicos e privados). A Diretoria de Comunicação trabalha com o intuito de

\footnotetext{
${ }^{8}$ A evolução das sociedades na segunda metade do século $X X$ clarifica a importância do papel que a memória coletiva desempenha [...] a memória coletiva faz parte das grandes questões das sociedades desenvolvidas e das sociedades em vias de desenvolvimento, das classes dominantes e das classes dominadas, lutando todas pelo poder ou pela vida, pela sobrevivência e pela promoção. (LE GOFF, 2003, p. 475)
} 
fortalecer as ações que já vêm sendo realizadas, além de desenvolver uma Política de Comunicação para a UFCA. (UNIVERSIDADE FEDERAL DO CARIRI, documento eletrônico sem paginação).

$\mathrm{Na}$ dinâmica da Instituição, o percurso das fotografias tem início com a solicitação de cobertura à DCOM e com a definição do cronograma de eventos. A partir daí os profissionais do setor acompanham os eventos, fazendo registros fotográficos dos acontecimentos e fatos que resultam na produção do material composto por fotografias em arquivos digitais. O material é analisado pelos jornalistas que selecionam as fotografias que irão compor as matérias e que serão disponibilizadas nos canais de comunicação oficial da UFCA, tais como portal $^{9}$ e página do Facebook ${ }^{10}$.

O material fotográfico é inserido no banco de imagens da rede social Flickr desde dezembro de 2014, quando a DCOM criou uma página na rede com o intuito de hospedar as fotografias da UFCA e disponibilizá-las para visualização. Durante grande parte deste período não havia na estrutura de pessoal do Setor servidores especificamente designados para a atividade de registro e de tratamento do material fotográfico, como fotógrafos e bibliotecários. Somente a partir de dezembro de 2016 a DCOM criou a Divisão de Fotografia, sob a responsabilidade de uma servidora com formação na área de fotografia, que treina e supervisionar as atividades dos bolsistas que realizam os registros e a inserção das imagens no Flickr. O processo de tratamento das fotografias na UFCA não possui critérios para a descrição das imagens. O conjunto de imagens resultantes de um acontecimento relacionado à Instituição é inserido na base Flickr e são preenchidas informações em campos fixos da base como título do álbum, notas e tags sem nenhum tipo de sistematização ou padronização. Essas informações são coletadas junto ao responsável pelo registro fotográfico ou a outros servidores da DCOM ou do setor ligado ao evento/acontecimento. $\mathrm{Na}$ verificação do conjunto de álbuns e fotografias presentes na página da UFCA é possível identificar que nem sempre todos os campos fixos são preenchidos.

Dada a natureza e extensão deste trabalho, a seguir será apresentada a

\footnotetext{
9 www.ufca.edu.br

${ }^{10} \mathrm{https}: / /$ www.facebook.com/UniversidadeFederaldoCaririOficial/
} 
captura das telas da base Flickr que expõe uma das fotografias do corpus de análise da pesquisa (Figura 1) e o recorte dos campos destinados à exibição do título do álbum, das notas e das Tags, preenchidos pelos colaboradores da DCOM (Figura 2). Em seguida apresentamos o quadro de análise (Quadro 2) das fotografias, proposto na metodologia, com a indexação realizada e as palavras-chave selecionadas de acordo com a proposição dos teóricos.

Figura 1 - Fotografia 1

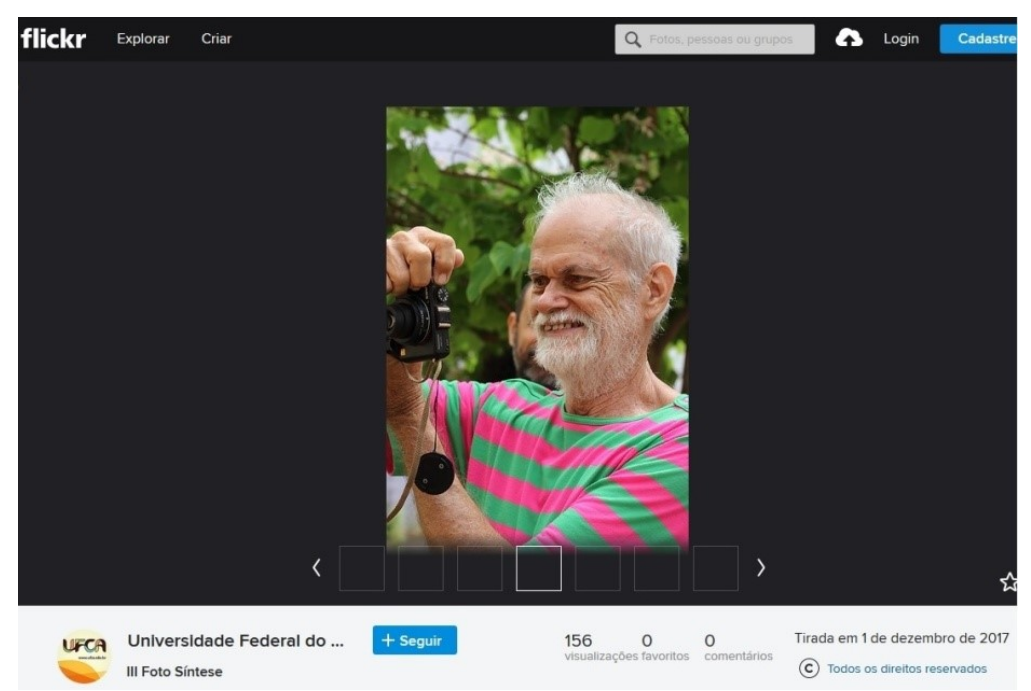

Fonte: (base Flickr, 2018).

A figura 1 apresenta apenas uma imagem com a nomenclatura de um evento, a saber "III Fotos Síntese". Não possibilitando nenhuma informação a mais para a recuperação da imagem.

Figura 2 - Tags da Fotografia 01

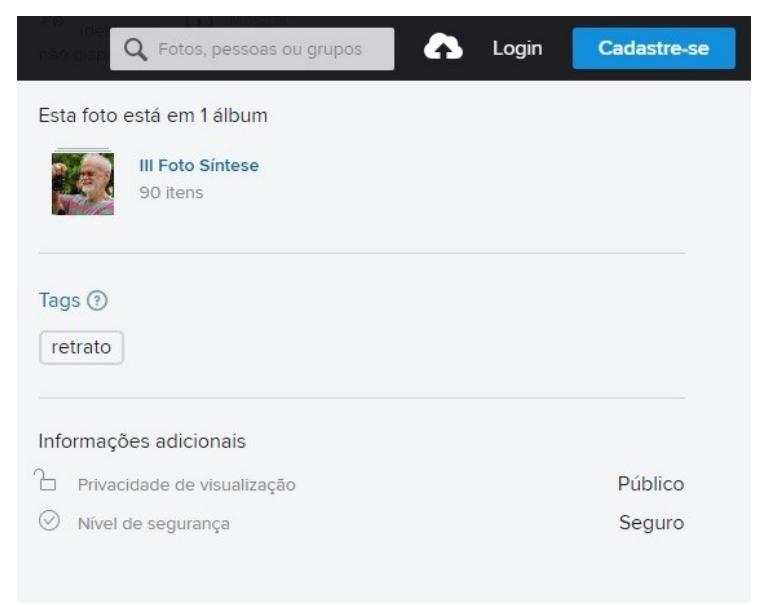

Fonte: (base Flickr, 2018). 
Na figura 2 há apenas uma Tag "retrato", que indica uma possibilidade muita genérica para a recuperação dessa imagem que, analisada de maneira mais completa, respondendo a questões básicas para identificação informacional (quadro 2), possibilitaria uma recuperação e compartilhamento mais significativos.

\section{Quadro 2: Indexação da Fotografia 1}

\begin{tabular}{|l|l|l|l|l|l|}
\hline & $\begin{array}{l}\text { Qategorias } \\
\text { Quem/o que }\end{array}$ & Onde & Quando & Como & \\
\hline $\begin{array}{l}\text { Pessoa; } \\
\text { ge }\end{array}$ & $\begin{array}{l}\text { Homem; } \\
\text { Câmera } \\
\text { fotográfica }\end{array}$ & $\begin{array}{l}\text { Ar livre } \\
\text { UFCA; }\end{array}$ & Dia & $\begin{array}{l}\text { Com câmera } \\
\text { na mão }\end{array}$ & $\begin{array}{l}\text { Pré- } \\
\text { iconográfico }\end{array}$ \\
\hline $\begin{array}{l}\text { De } \\
\text { específico }\end{array}$ & $\begin{array}{l}\text { Campus Juazeiro } \\
\text { José Albano; }\end{array}$ & $\begin{array}{l}\text { do Norte; } \\
\text { José Albano fotografando durante atividade do evento III Foto }\end{array}$ & Iconográfico \\
\hline Sobre & $\begin{array}{l}\text { Síntese na UFCA. } \\
\text { Iconológico }\end{array}$ \\
\hline
\end{tabular}

Fonte: Elaborado pelas autoras, 2018.

TERMOS FOTOGRAFIA 1: PESSOA; HOMEM; JOSÉ ALBANO; CÂMERA FOTOGRÁFICA; FOTOGRAFIA; III FOTO SÍNTESE; JUAZEIRO DO NORTE; UFCA; 2017.

As figuras 1 e 2 nos dão uma noção das marcações que foram utilizadas para descrição da fotografia. É possível observar, com base no quadro 2, as possibilidades de recuperação dessa imagem que não foram consideradas, tendo dentre estas a menção da pessoa que aparece na fotografia e a descrição de que se trata de um evento, bem como a data de sua ocorrência, entre outras informações. Este é um exemplo que reflete as demais 29 imagens avaliadas ${ }^{11}$, que receberam tags genéricas e desconsideraram informações importantes como nomes de pessoas e eventos e datas. Isso expõe um sério comprometimento quanto à memória institucional, tendo em vista que as imagens são traços históricos da Universidade.

\footnotetext{
11 Para visualizar todas as imagens analisadas, acesse a pesquisa completa em: http://sites.ufca.edu.br/ppgb/wp-content/uploads/sites/20/2019/06/NOGUEIRA_Fotografia-emem\%C3\%B3ria-institucional_2018.pdf
} 


\section{INFERINDO RESULTADOS}

A análise do percurso de indexação das fotografias na UFCA nos permite inferir que está em curso um processo de aprendizagem, sobretudo se pensamos o breve tempo de existência da instituição, que expressa acertos, mas também desafios teóricos-metodológicos que envolvem a construção da memória institucional a partir do documento fotográfico.

Aprender, na travessia, a ler os acertos e equívocos, não como situações estanques, mas como lugares de partida para o aperfeiçoamento da análise documentária de forma contextualizada é uma dimensão a ser incorporada ao trabalho dos setores envolvidos com o trato do material fotográfico produzido pela Instituição. Em diálogo com esse desafio partilhamos alguns dos resultados que a pesquisa nos permitiu evidenciar e expomos uma análise mediante à sugestão de ações/atividades para estas observações:

a) A análise conceitual foi identificada como o passo que traz maior dificuldade ao processo de indexação de documentos fotográficos. Assim, sugere-se que nesse momento se busque identificar a essência, o que verdadeiramente está expresso nas fotografias através de uma leitura apurada, tanto da imagem, quanto do texto da legenda, elaborando o máximo de significações, de modo a construir uma interpretação mais fiel possível, dentro das limitações impostas por seu caráter subjetivo e pelo que está sendo retratado;

b) A verificação da página da UFCA no Flickr indicou que na maioria das fotografias selecionadas não houve a inserção das legendas e quando estas aparecem descrevem de forma geral o álbum e para algumas fotografias não são representativas, pois não condizem com o que verdadeiramente os fotógrafos capturaram, baseando-se unicamente na temática geral da pauta. Como medida de reparação desse lapso informacional as legendas devem ser utilizadas como fonte importante de contextualização e como fornecedora de possíveis descritores que auxiliem no momento da tradução;

c) A etapa de tradução requer um conhecimento acumulado. Sendo assim, 
somente providos de todo um apanhado informacional, presente nos metadados, nas pautas, nas legendas e nas próprias fotografias a serem indexadas, deve-se partir para a etapa de tradução em que são atribuídos termos representativos da temática dos documentos;

d) Em diálogo com a equipe da DCOM com o propósito de complementação de informações verificamos que no momento da leitura, os profissionais deparam-se com uma série de informações textuais e imagéticas que desencadeiam um processo interpretativo. Aliando a percepção de códigos visuais, presentes nas fotografias, e códigos textuais, presentes nas legendas, os indexadores vão em busca de uma interpretação e representação que contemple tanto os objetos expressos na fotografia como o seu contexto, desde que disponham de instrumentos de padronização;

e) No momento da indexação os profissionais devem aliar a observação do documento visual à leitura da legenda, de modo a selecionar e atribuir termos baseados em linguagem natural (palavras-chave) ou em um vocabulário controlado (descritores). A seleção dos termos, como propõe a literatura, visa à representação da imagem, descrevendo "de que trata" e pauta-se, também, na preocupação de selecionar termos que se adéquem à forma como os usuários buscariam determinada fotografia. Aspectos estes que devem levar em consideração o perfil dos usuários e as atividades realizadas por eles, que estão intimamente relacionadas ao conteúdo documental que é tratado, organizado e disponibilizado;

f) A indexação depende e revela uma linguagem. Dito isso, percebemos que a indexação deve levar em conta o vocabulário dos utilizadores e os potenciais pedidos que serão formulados pelo grupo de usuários. Nesta perspectiva, buscamos observar e coletar informações acerca dos meios através dos quais os responsáveis pela indexação adequavam a terminologia e a escolha de termos ao seu público alvo. No decorrer dos processos de tratamento documental do Setor sempre se fez uso de linguagem natural e não houve até o momento nenhum encaminhamento no sentido de desenvolver um vocabulário controlado para a indexação 
dos documentos fotográficos;

g) Constatou-se que no caso dos documentos fotográficos produzidos pela DCOM outra questão importante refere-se ao fato de os usuários, muitas vezes, serem os autores e personagens das fotografias. Dessa forma, representam uma clientela bem mais exigente, que por já saber da existência de um item fotográfico na base pode apresentar como critérios para a formulação de estratégias de buscas, detalhes específicos que podem ou não terem sido contemplados no momento da indexação, impulsionando os indexadores a se colocarem no lugar dos usuários no momento da indexação, como forma de contemplar aspectos que possivelmente seriam procurados, empreendendo uma aproximação com os prováveis pedidos/necessidades dos usuários;

h) Por fim, em diálogo com um dos questionamentos da pesquisa que inquiria sobre a segurança oferecida pela base de dados utilizadas pela DCOM, no caso o Flickr, da empresa Yahoo, avaliamos que se por um lado a inserção de imagens em uma rede marcada pela interatividade e acessada mundialmente possibilita a disponibilização e divulgação do conteúdo imagético e memorialístico da UFCA nos moldes da era digital, por outro traz uma reflexão em torno das problemáticas relacionadas à segurança da informação. Mesmo cientes que a DCOM realiza cópia de segurança do material fotográfico, todos os esforços relacionados à sua descrição, possibilitados pelos processos de indexação, podem ser perdidos no momento que o Yahoo Brasil resolver descontinuar o serviço. Não há garantias quanto à segurança do conteúdo e interoperacionalidade de sistemas que possibilitem a migração de dados utilizados para sua representação. Tais questões devem ser consideradas pela UFCA no sentido de planejamento e investimento em uma base de dados que de fato seja pensada de acordo com as características e necessidades da instituição e que ofereça segurança ao conteúdo imagético e memorialístico. 


\section{CONSIDERAÇÕES FINAIS}

Buscamos, com esse trabalho, reconhecer a potência do documento fotográfico como elemento constituinte da memória institucional. A imagem nesse contexto soma-se ao texto, e passa a ser parte desse texto a contar a história de indivíduos, de eventos, do cotidiano e do extraordinário. Nessa busca, a visualização dos procedimentos relacionados ao tratamento e armazenamento das fotografias da UFCA possibilitou um melhor entendimento sobre a realidade estudada, através da verificação das condições de representação e recuperação deste material organizado pela Instituição, e fomentou a proposição de critérios e direcionamentos no sentido de um melhor aproveitamento informacional, possibilitado pelo efetivo acesso ao conjunto documental e memorialístico.

Através da análise documentária do corpus de pesquisa foi possível visualizar e estruturar estratégias de categorização e representação indexal que contemplam os aspectos relacionados ao conteúdo das fotografias. A análise referente às Tags nos revelou que não há uma frequência de inserção, o que demonstra grande fragilidade na representação das fotografias. Diante da inexpressiva quantidade de Tags e por considerarmos as categorias apresentadas como categorias básicas para identificação de informações relativas às imagens, realizamos o processo de indexação das fotografias no sentido de demonstrar e recomendar a descrição que contempla tais critérios de análise, pois resultam em um melhor nível de representação e recuperação informacional. Diante da inexistência de qualquer direcionamento acerca dos critérios de indexação na DCOM, das percepções e das recomendações apontamos a necessidade imprescindível de elaboração de uma política de indexação, que levando em consideração os pressupostos da literatura, as características e as necessidades da Instituição, deve apresentar os procedimentos norteadores de todos os processos de tratamento dos documentos fotográficos. Assim, sugerimos a criação de um documento em que sejam elencados todos os aspectos importantes em relação ao procedimento de tratamento indexal dos documentos imagéticos, considerado indispensável para que se realize um trabalho alicerçado em bases sólidas que confiram 
credibilidade, coerência e qualidade ao trabalho realizado pelos profissionais.

Tratando-se de imagens produzidas em âmbito institucional o profissional da informação responsável pela atribuição dos termos deverá possuir familiaridade com as personagens, com as atividades e com os espaços componentes das fotografias como forma de minimizar as dificuldades atribuídas à subjetividade das imagens. Durante sua análise o responsável pela indexação deve perceber a imagem e representá-la buscando contemplar aspectos que atendam ao coletivo, que levem em consideração as características e especificidades da Instituição e as necessidades do público. As informações sobre suas personagens, sobre as ações retratadas, mesmo quando não disponíveis explicitamente devem ser buscadas pelo indexador no ambiente institucional, pois tais informações serão essenciais para a representação e recuperação das imagens. O detalhamento em níveis específicos, com riqueza de detalhes, de elementos objetivos e de elementos relacionados ao sentido e ao contexto são os componentes da significação da fotografia e os responsáveis pela carga informacional e memorialística dos documentos que comporão o acervo fotográfico da Instituição.

Salientamos a necessidade de padronização em relação aos termos utilizados para a representação das fotografias, que deve ser balizada por um vocabulário controlado que estabeleça os critérios de uso da linguagem no sentido de uma maior uniformidade e de melhores níveis de precisão e revocação nos processos de busca que resultam em uma melhor recuperabilidade.

Percebeu-se, também, uma escassez de recursos humanos que compromete as atividades relacionadas à produção e tratamento fotográficos, mas destaca-se a iniciativa de criação do Núcleo de Fotografia, sob a chefia de uma profissional com formação na área de fotografia, como um ponto positivo e componente importante para a Instituição. Contudo, ressaltamos a necessidade de incorporação de mais profissionais que possuam conhecimento na área de produção e representação fotográfica para a sistematização de práticas e processos que ofereçam melhores condições para o tratamento e efetivo uso das fotografias. A sazonalidade característica de colaboradores que 
desempenham atividades em regime de bolsas não favorece os processos de indexação, que requerem um conhecimento apurado sobre a Instituição e sobre seus personagens e familiaridade com os processos.

Ademais, enfatizamos que o uso inadequado das ferramentas de um sistema e a utilização de processos de representação que se furtam às questões relacionadas aos estudos, critérios e direcionamentos propostos pela análise documentária fragilizam, sobremaneira, a recuperação dos documentos e, consequentemente, a constituição e preservação da memória institucional.

Diante do exposto, espera-se contribuir e fomentar discussões sobre a representação dos documentos fotográficos na UFCA e em outras instituições que lidam com tais processos, bem como alertar sobre a segurança desses materiais e sua importância para constituição da memória institucional da Universidade. Reforçamos o entendimento sobre o potencial documental das fotografias e sobre a necessidade de produzir material reflexivo que gere subsídios para a proposição e adequação dos processos de tratamento de acervos fotográficos institucionais e que pautem direcionamentos para um melhor aproveitamento, disponibilização e preservação do material memorialístico da UFCA e de outras instituições e organizações.

\section{REFERÊNCIAS}

BARBOSA, Andréia Arruda. O lugar da memória institucional nas organizações complexas. In: CONGRESSO BRASILEIRO CIENTÍFICO DE COMUNICAÇÃO ORGANIZACIONAL E DE RELAÇÕES PÚBLICAS, 4., 2010. Anais [...]. Porto Alegre: Abrapcorp, 2010. Disponível em:

http://www.abrapcorp.org.br/anais2010/GT2/GT2_Andreia.pdf. Acesso em 20 abr. 2019.

BARTHES, Roland. A câmara clara: nota sobre a fotografia. Rio de Janeiro: Nova Fronteira, 1984.

BLÉRY, Giselle. La mémoire photographique: étude de la classification des images et analyse de leur contenu à l'aide de l'informatique. Bulletin Interphotothèque, Paris, n. 41, p. 9-34, 1981.

BRASCHER, Marisa; CAFE, Lígia. Organização da informação ou organização do conhecimento?. In: ENCONTRO NACIONAL DE PESQUISA EM CIÊNCIA 
DA INFORMAÇÃO, 9., 2008, São Paulo. Anais [...]. Brasília: ANCIB, 2008.

BRASIL. Lei $\mathbf{n}^{0}$ 12.826, de 5 de junho de 2013. Dispõe sobre a criação da Universidade Federal do Cariri - UFCA, por desmembramento da Universidade Federal do Ceará - UFC, e dá outras providências. Brasília, 5 de junho de 2013; $192^{\circ}$ da Independência e $125^{\circ}$ da República.

BRIET, Suzanne. Qu'est-ce que la documentation? Paris: Éditions Documentaires Industrielles et Técnicas, 1951.

DUBOIS, Philippe. O ato fotográfico. 14. ed. Campinas: Papirus Editora, 1994.

GOUVÊA, Cleber; LOH, Stanley. Folksonomias: identificação de padrões na seleção de tags para descrever conteúdos. RESI: Revista Eletrônica de Sistemas de Informação, Campo Largo, v. 6, n. 2, p. 1-8, 2007. Disponível em: http://www.periodicosibepes.org.br/index.php/reinfo/article/view/214/118 Acesso em: 27 nov. 2018.

KOSSOY, B. Realidades e ficções na trama fotográfica. 4. ed. São Paulo: Ateliê Editorial, 2009.

LANCASTER, F. W. Indexação e resumos: teoria e prática. 2. ed. Brasília: Briquet de Lemos, 2004.

LE GOFF, Jacques. História e memória. Campinas: UNICAMP, 2003.

MADIO, Telma Campanha de Carvalho; FUJITA, Mariângela Spotti Lopes. Importância da gênese documental para identificação de acervos fotográficos. Ibersid: revista de sistemas de información y documentación, v. 2, p. 251-261, 2008. Disponível em: https://ibersid.eu/ojs/index.php/ibersid/article/view/2244 Acesso em: 26 jul. 2019.

MANINI, Míriam Paula. Análise documentária de fotografias: um referencial de leitura de imagens fotográficas para fins documentários. 2002. $226 \mathrm{f}$. Tese (Doutorado em Ciências da Comunicação) - Departamento de Biblioteconomia e Documentação, Universidade de São Paulo, São Paulo, 2002.

MARCONI, Marina de Andrade; LAKATOS, Eva Maria. Fundamentos de metodologia científica. 7. ed. São Paulo: Atlas, 2010.

ORTEGA, Cristina Dotta; LARA, Marilda Lopes Ginez de. A noção de documento: de Otlet aos dias de hoje. In: CONGRESSO ISKO-SPAIN, 9., 2009. Anais [...]. Espanha, 2009. Disponível em: http://www.iskoiberico.org/wpcontent/uploads/2014/09/528-544_Dotta-Ortega.pdf Acesso em: 26 jul. 2019.

PANOFSKY, Erwin. Significado nas artes visuais. 2.ed. São Paulo: Perspectiva, 1979. 
POLLAK, Michael. Memória, esquecimento, silêncio. Estudos Históricos, Rio de Janeiro, v. 2, n. 3, 1989, p. 3-15. Disponível em:

http://www.uel.br/cch/cdph/arqtxt/Memoria_esquecimento_silencio.pdf Acesso em: 02 jun. 2019.

POSSAMAI, Zita Rosane. Fotografia, história e vistas urbanas. São Paulo, História. v. 27, n. 2, p. 253-277, 2008. Disponível em: http://www.scielo.br/pdf/his/v27n2/a12v27n2.pdf Acesso em: 02 jun. 2019.

SHATFORD, Sara. Analyzing the subject of a picture: a theoretical approach. Cataloging \& Classification Quarterly, v. 6, n. 3, p. 39-62, 1986.

SMIT, Johanna W. A representação da imagem. INFORMARE- Cadernos do Programa de Pós-Graduação em Ciência da Informação, Rio de Janeiro, v. 2, n. 2, p. 28-36, jul./dez. 1996.

SMIT, Johanna W. A análise da imagem: um primeiro plano. In: SMIT, Johanna W. Análise documentária: a análise da síntese. Brasília: IBICT, 1987.

UNIVERSIDADE FEDERAL DO CARIRI. Diretoria de Comunicação - DCOM. Disponível em: https://www.ufca.edu.br/instituicao/administrativo/estruturaorganizacional/orgaos-suplementares/dcom/ Acesso em: 30 maio 2019.

\title{
THE INDEXAL TREATMENT OF PHOTOGRAPHS FOR COMPOSITION OF THE INSTITUTIONAL MEMORY
}

\begin{abstract}
Introduction: Photographic images are important documents, possessing valuable informational, historical and cultural potential, which are constituents of memory. In this sense, this study discusses the value of photography as a constituent document of institutional memory, presenting relevant aspects of the literature on documentary analysis, with emphasis on the indexing process, having as object of investigation the collection of digital photographs from the Universidade Federal do Cariri (UFCA). Objective: To develop categorization and indexal representation strategies that include aspects related to the content of UFCA photographs, stored in Flickr platform. Methodology: Through a qualitative approach, a documentary and interpretative analysis related to the processes of production and representation of UFCA photographs was performed. Results: This analysis allowed the identification and presentation of the specificities of this type of document and its special logic for treatment and contributions to the construction of photographic image indexing criteria, which aim to guide the development of an indexing policy for the Institution. Conclusions: Given the lack of any direction regarding the indexing criteria for the UFCA digital photographic collection, we suggest the creation of a document that lists the important aspects in relation to the indexal treatment procedure of image documents, considered indispensable to ensure the preservation of the institutional memory of the university.
\end{abstract}

Descriptors: Documentary analysis. Photography. Indexing. Institutional Memory. 


\title{
TRATAMIENTO INDEXAL DE FOTOGRAFÍAS PARA COMPOSICIÓN INSTITUCIONAL DE MEMORIA
}

\begin{abstract}
RESUMEN
Introducción: Las imágenes fotográficas son documentos importantes, que poseen un valioso potencial informativo, histórico y cultural, que son constituyentes de la memoria. En este sentido, el estudio analiza el valor de la fotografía como documento constitutivo de la memoria institucional, presentando aspectos relevantes de la literatura sobre análisis documental, con énfasis en el proceso de indexación, teniendo como objeto de investigación la colección de fotografías digitales de la Universidade Federal do Cariri. (UFCA). Objetivo: Desarrollar estrategias de categorización y representación indexada que incluyan aspectos relacionados con el contenido de las fotografías de la UFCA, almacenadas en la plataforma Flickr. Metodología: A través de un enfoque cualitativo, se realizó un análisis documental e interpretativo relacionado con los procesos de producción y representación de las fotografías de la UFCA. Resultados: Este análisis permitió la identificación y presentación de las especificidades de este tipo de documento y su lógica de tratamiento especial y las contribuciones a la construcción de los criterios de indexación de imágenes fotográficas, cuyo objetivo es guiar el desarrollo de una política de indexación para la Institución. Conclusiones: Dada la falta de orientación sobre los criterios de indexación para la colección fotográfica digital UFCA, sugerimos la creación de un documento que enumere los aspectos importantes en relación con el procedimiento de tratamiento indexado de los documentos de imagen, que se consideran indispensables para garantizar la conservación de memoria institucional de la universidad.
\end{abstract}

Descriptores: Análisis documental. Fotografía. Indexación. Memoria institucional.

Recebido em: 26.07.2019

Aceito em: 09.09.2019 